\title{
E-democracy: potential for Political Revolution?
}

\author{
Karen McCullagh ${ }^{1}$
}

\begin{abstract}
This article focuses on the traditional notions of democracy and governance in the context of the recent shock first-round election results in France. The results prima facie suggest voter apathy and disengagement from the democratic process. However, the spontaneous street protests confirm that voters are not apathetic about democracy, rather they are dissatisfied with the current model of government and the unresponsive nature of government. It will be argued that the interactive nature of Internet technology has the potential to reinvigorate the democratic process and re-engage citizens positively in political life.
\end{abstract}

\section{Introduction}

France's 40 million voters yesterday unveiled the full and shocking extent of their political disenchantment, apparently sending the veteran far-right leader Jean-Marie Le Pen through to the second round of the Presidential elections to face the outgoing Jacques Chirac. Tens of thousands of people took to the streets of Paris in spontaneous protest ... The exit polls, which have proved accurate in all previous elections showed that more voters stayed at home than ever before in a presidential election, putting the abstention rate at $28 \%{ }^{2}$ It is not just as a result of increasing far right support but a failure on the part of Mr Chirac and Mr Jospin (and the wider French political establishment) to engage enough of the electorate. ${ }^{3}$

In this article I intend to explore the potential reasons underpinning

\footnotetext{
${ }^{1}$ Karen McCullagh, LLB, LLM, Solicitor, Research Assistant at School of Law, Queen's University, Belfast. Email: k.mccullagh@qub.ac.uk

${ }^{2}$ Henley, J. 'Le Pen vote shocks France,' The Guardian (2002, 22nd April).

${ }^{3}$ Jeffrey, S. 'Elections in France,' The Guardian (2002, 22nd April).
} 
such an election result, and in particular explore the assertion of Coleman that:

New relationships between citizens and institutions of government must emerge if a crisis of democratic legitimacy is to be averted ... old styles of representation have come under pressure to change. There is a pervasive contemporary estrangement between representatives and those they represent, manifested in almost every country by falling voter turnout; lower levels of public participation in public life; public cynicism towards political institutions and parties. ${ }^{4}$

It will be argued that Internet technology has the potential to reinvigorate the democratic process and re-engage citizens positively in political life, provided that the democratising potential of the Internet is properly harnessed. Indeed Rheingold envisages a utopian electronic agora, an 'Athens without slaves', believing that Internet technology;

if properly understood and defended by enough citizens, does have a democratising potential in the way that alphabets and printing presses had democratising potential. ${ }^{5}$

\section{Utopian Democratic Vision}

In order to demonstrate the positive potential of the Internet, the traditional notions of democracy and governance will be explored and conditions necessary to harness the democratic potential of the Internet will be identified. Rheingold's vision of democracy facilitated by Internet technology is based upon two premisses. First, the Habermasian 'public sphere' concept, and secondly, the potential role of the Internet as a locus for democratic discussion and activity. He builds upon the Habermasian concept of 'public sphere,' that is,

the idea of modern representative democracy as it was first conceived by enlightenment philosophers included a recognition of a living web of citizen to citizen communications known as civil society or the public sphere. ${ }^{6}$

Habermas develops the normative notion of public sphere as an element of social life where citizens can exchange views on matters of importance to the common good, so that public opinion can be formed. He posits that the public sphere is formed when people gather together to discuss issues of

\footnotetext{
${ }^{4}$ Coleman, S. \& Gotze, J. 'Bowling Together: Online Public Engagement in Policy Deliberation' (2001) Hansard Society, 4.

${ }^{5}$ Rheingold, H. The Virtual Community (Massachusetts: Addison-Wesley Publishing Company 1993) 276.

${ }^{6}$ Rheingold, H. 279.
} 
political concern. ${ }^{7}$ The discussion must take the form of rational-critical debate. The debate is governed by a set of rules that prohibit the use of emotion or emotive language and focus upon the rationality of the context. ${ }^{8}$ Criticism is a vital element of the debate process, so that the proposals can be tested, and more importantly, participants can, through the debate process alter their opinions and discover a meaning (consensual). This conceptualisation of the public sphere requires individual citizens to view themselves as important participants in political life, to take the concept of participation seriously, and to believe that they have a duty to contribute for the good of society. Although direct participation by all citizens is the ideal of democracy, representative democracy was deemed to be necessitated by the practical impossibility of giving all citizens an equal opportunity to participate in the collective debate. Thus he contends that by the nineteenth century the public's opinion became an 'officially designated discussion partner' ${ }^{9}$ of Parliament. Speeches were made, as they are today, with the public in mind, and gradually their role in political life assumed greater influence.

Habermas also emphasised the critical role of the media in the public sphere. He contends that the development of newspapers in the early seventeenth century created a role for the media;

for the first time established as a genuinely critical organ of a public engaged in critical political debate: as the fourth estate. ${ }^{10}$

Such media fostered the public sphere by highlighting political controversy, so those individuals could use this information to engage in constructive rational-critical debates.

\section{Democratic Deficiencies}

However, Blumler and Coleman assert that;

A conspicuous weakness in the 20th Century representative democracies has been the absence of robust public deliberation. An assumption has prevailed that fair elections plus well-run parliaments equals the democratic ideal, matched all too often by a complimentary belief that

\footnotetext{
${ }^{7}$ His work relies on a description of the 17 th and 18 th centuries when coffeehouses, societies and salons became the centre of debate, and extends this to an ideal of participation in the public sphere for today.

${ }^{8}$ Participants should have a common interest in the truth, which means that status differentials are bracketed (so that participants speak as if they are equals).

${ }^{9}$ Habermas, J. (1990) p. 43 in Peters, J. 'Distrust of Representation' (1993) Media, Culture \& Society Vol. 15 (4) 564.

${ }^{10}$ Habermas, J. in Calhoun, C. Habermas and the Public Sphere (Massachusetts: MIT Press 1993) 60.
} 
the public is not very good or interested in discussing the politics that affect it. ${ }^{11}$

Indeed, theorists have long argued against public involvement in the discussion of policy issues. Lippmann ${ }^{12}$ feared that high levels of public involvement in the political process would lead to a decline in political competence. He argued that participatory democracy was unworkable, that the democratic public was a myth, and hence that government should be delegated exclusively to political representatives and their expert advisors. He based his arguments on empirical evidence about the efficacy of political propaganda and mass advertisement in shaping people's way of thinking, and contended that public opinion is highly shaped by leaders, as ordinary citizens have no sense of objective reality, since their ideas are merely stereotypes manipulated by leaders. Thus the concept of deliberative, participatory democracy was an impossible dream.

Likewise, Habermas ${ }^{13}$ argues that as the public sphere gradually expanded to include more participants, there was a corresponding decline in the quality of discourse. Thus Lippmann advocated a model of 'democratic realism' based on political realism and technical expertise. In his view, the most favourable alternative to participatory democracy consisted of a technocracy in which government leaders are guided by experts whose objectives and disinterested knowledge extend beyond the narrow views and parochial self-interests of average citizens organised in local communities. In contrast, Dewey ${ }^{14}$ (writing in the pre-Internet era) opined that the problem was not that the public lacks the ability to be informed, rather no mechanism had yet been devised which would adequately inform the public. In this respect the media failed. Instead of reporting on politics and acting as an agency of representation organised to allow diverse social groups to express their views, the media tended to commodify news. Dahlgren ${ }^{15}$ argues that events are manipulated and sensationalised to ensure maximum TV impact. Public debate on TV and in newpapers gives the illusion of participation through invited audiences which encourages citizens to feel as though their democratic rights are being exercised, but in reality bears little resemblance to the rarionalcritical debate favoured by Habermas.

However, the dissatisfaction expressed by the French voters is not an aberrant result. Rather it is a reflection of growing, endemic disenchantment of the public in many democracies. As Snellen observes, the inherent weakness of existing democratic arrangements stem from perceptions that:

\footnotetext{
${ }^{11}$ Blumler, J. G. \& Coleman, S. 'Realising Democracy Online: A Civic Commons in Cyberspace' (2001) IPPR/Citizens Online Research, Publication No.2 (March) 6.

${ }^{12}$ Lippmann, W. Public Opinion (New York: MacMillan 1992).

${ }^{13}$ Habermas, J. in Calhoun, C. (1993) p.3.

${ }^{14}$ Dewey, J. The Public and its Problems (New York: Holt 1927) 365.

${ }^{15}$ Dahlgren, P. Television and the Public Sphere: Citizenship, Democracy and the Media. (London: Sage Publications 1995) 66.
} 
Members of the representative assemblies represent partisan interests under the guise of general interest, that they tend to follow only their own partial understanding of what is good for their constituencies, and that they are more responsive to the requirement of the political party they belong to than to the citizens whose mandate they received. ${ }^{16}$

It is arguable that democratic deficits have been precipitated by two identifiable trends in world economies, namely Globalisation and Marketisation. Globalisation ${ }^{17}$ opened up opportunities for private transnational actors to establish standards and policies that were previously under the remit of central government. Marketisation: Strange posits that the balance between states and markets has shifted since the1970's in a way that renders the State just one source of power, ${ }^{18}$ as power has diffused to a variety of private actors 'leaving a yawning hole of non-authority or ungovernance. ${ }^{19}$ Indeed, the state sector reforms of the 1980's and 1990's concentrated on decentralisation of government powers. Whilst decentralisation improved speed and efficiency at departmental level, it made intergovernmental relations more bureaucratic, and therefore unresponsive to the public. Consequently there have been growing complaints about how governments conduct their affairs. Governments are in effect monopolies with inherent weaknesses. It is arguable that the lack of competition causes governments to be inefficient, slow to innovate and bear excessive operating costs. Government is often perceived to be inaccessible, excessively complex and constrained by 'red-tape', thereby rendering it unresponsive to the needs of citizens. It is criticised for being slow to respond, for failing to engage citizens in the democratic process and for imposing 'one-size-fits-all' solutions. As Dewey observed;

No government by experts in which the masses do not have the chance to inform the experts as to their needs can be anything but an oligarchy managed in the interest of the few ... the essential need ... is the improvement of the methods and conditions of debate, discussion and persuasion. That is the problem of the public. ${ }^{20}$

The British Government appears to have recognised the democratic

\footnotetext{
${ }^{16}$ Snellen, I. 'ICTs And The Future of Democracy' (2000-2001) International Journal of Communications, Law and Policy Issue: Winter 1.

${ }^{17}$ The increasing speed and scale of transfers of goods, people and information across borders with the effect of decreasing the effect of distance.

${ }^{18}$ Strange, S. The Retreat of the State: the diffusion of power in the World Economy (Cambridge: Cambridge University Press 1996) - observes that power has diffused from governments to markets in critical functions such as maintaining the value of the currency, choosing the form of the economy etc.

${ }^{19}$ Strange, S. 14.

${ }^{20}$ Dewey, J. (1927) 207-208.
} 
failings of the current model of democracy, and that the Internet technologies herald the potential for radical reform which would reinvigorate the democratic process and re-engage citizens in the political process, as indicated in a speech by Mr Mandelson, M.P.;

It may be that the era of pure representative democracy is coming slowly to an end. ${ }^{21}$

Mandelson proposed to deal with the demise of traditional constitutionalism and democratic processes by developing Internet referendums, citizen juries, and a range of direct democracy techniques enabled by the 'information revolution'. The Information Revolution refers to the dramatic decrease in the cost of computers and communications and the effect this has on the economy, society and governments. As computing power $^{22}$ has decreased in cost, computers shrunk in size and become more widely distributed; rather than reinforcing centralisation and bureaucracy of governments, the new technologies have tended to encourage network organisations, new types of community and generate demands for different roles of government and methods of 'governance'.

\section{Governance}

The word 'governance' derives from the Greek 'kubernan' meaning 'to steer a ship.' In 20th Century modern organisations it was often used to refer to the arrangement of power for directing and controlling other people. Following privatisation of public institutions in the 1980's, when market forces expanded within an increasingly privatised economy, the term governance came to reflect the new relationship of government and citizens which involved relating to the public as 'customers/consumers'. Consequently the Bangemann Report ${ }^{23}$ fails to mention the democratic potential of the Internet. Instead it focuses on government as administrative services which need to be improved in order to maximise efficiency and reduce costs. Indeed, it is this concept of citizens as 'consumers/ customers' that is addressed in the provisions of the White Paper: Modernising Government, 1999. ${ }^{24}$ This outlines the Government's inten-

\footnotetext{
${ }^{21}$ Mandelson, P. The Times (1998, 20th March) (keynote speech given to a seminar in Bonn)

${ }^{22}$ Greenwood, J. The Third Industrial Revolution: Technology, Productivity and Income Inequality (Washington D.C. : AEI Press 1997) the price of a new computer has dropped by $19 \%$ since 1954, and information technologies have risen from $7 \%$ to about $50 \%$ of new investment.

${ }^{23}$ Bangemann Report 'Recommendations to the European Council: Europe and the global information society' Ch. 4 Application Nine, 26 http://www.rewi.hu.berlin.de/datenschutz/report.html

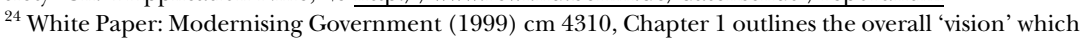
envisages a public sector 'with a culture of improvement, innovation and collaborative process' (para. 10) operating in a way that is 'as efficient, dynamic and effective as anything in the private sector' (para. 11). In Chapter 5 the emphasis is on how Government must modernise the business of government 'achieving joined up working between different parts of government and providing new, efficient and convenient ways for citizens and businesses to communicate with government and to receive services' (para. 5).
} 
tion to place services on-line, focusing on the administrative or businesslike role of government, and failing to address the issue of engaging citizens in the democratic process, a necessary element of representative democracy. Morison and Newman suggest that while the service role of government is important to citizens;

there seems little recognition that while these aims are worthy, even more may be possible by way of involving the citizen directly. ${ }^{25}$

It is suggested that Morison and Newman are correct in their observation that the focus of governments on aspects of service delivery;

misses an opportunity to use technologies to facilitate more direct forms of democracy and reinvigorate traditional representative democracy. ${ }^{26}$

Likewise, Coleman recognises that the government perceives citizens as customers and accordingly pitches reform on the basis of cost efficiencies and greater convenience. However, he posits that;

there is no intrinsic link between successful e-government and strengthened democracy. ${ }^{27}$

It is submitted that services such as the potential to complete and submit Tax returns online are unlikely to stimulate citizen participation in the democratic process. Accordingly it is argued that Governments need to appraise themselves of the potential of e-democracy and invest in technologies and mechanisms which would facilitate this process, rather than believing that simply by placing administrative services online citizens will be appeased and more approving of the current democratic process. As Clift succinctly stated;

We do not want governments to simply automate services without evaluation of what they might be doing right or wrong. ${ }^{28}$

\section{Democratic Potential of Internet technologies}

In this article I do not propose to dwell on the merits of placing services on-line. ${ }^{29}$ Instead, I wish to explore the democratic potential of Internet technology and what conditions must be satisfied to ensure re-invigoration

\footnotetext{
${ }^{25}$ Morison, J. \& Newman, D. R. 'On-line Citizenship: Consultation and Participation in New Labour's Britain and Beyond' (2001) International Review of Law, Computers E Technology Vol. 15 189, footnote 5.

${ }^{26}$ Morison \& Newman (2001) 171-172.

${ }^{27}$ Coleman, S. \& Gotze, J. 5.

${ }^{28}$ Clift, S. 'The E-Democracy E-Book: Democracy is online 2.0,' Chapter 2 http://www.publicus.net/ $\underline{\text { ebook }}$

${ }^{29}$ e.g. avoidance of queues, convenience, reduction in operating costs etc.
} 
of the democratic process. It is suggested that success is dependent upon a number of factors, which includes widespread adoption of Internet Technology, political leadership and sufficient funding. The UK is perceived to have several advantages in this respect, namely, digital expertise, high levels of computer literacy and high levels of computer access, and a Government committed to modernisation of the democratic process. One of the most important factors, which will determine the success of e-democracy, is the notion of 'citizenship'. Citizenship requires individual Internet users to play an active role in the democratic process, by engaging in online discussion forums, participating in debates and offering their expertise, so that issues may be explored and addressed in a consensual manner. The results of the French first round presidential elections prima facie suggest voter apathy and disengagement from the democratic process. However, the spontaneous street protests confirm that voters are not apathetic about democracy, rather they are dissatisfied with the current model of government and the unresponsive nature of government.

Thus, in order to re-invigorate the democratic process it will be necessary for citizens to re-engage in the democratic process. It is suggested that the interactive nature of the Internet will encourage citizens to participate in the democratic process. Moreover, it is suggested that a greater crosssection of the population will engage in the political discourse. Although the potential for online discussion forums involving people from different class, education, gender and racial backgrounds does not accord with the bracketed description of the normative Habermasian, democratic ideal, (where people engage as equals, rational argument prevails, the goal is consensus and the group mutually reach a decision) it is suggested that such forums allow a more representative model of democracy to emerge. Indeed, it is submitted that the focus of constitutional renewal should not be 'representation', rather it should be concerned with the issues of 'equality of access and participation' and 'fairness of discussion'. ${ }^{30}$ Thus Young argues that 'some groups sometimes deserve special rights' ${ }^{31}$ These rights might include consultation requirements, conditions of minimum consensus, as well as rights for particular groups and the imposition of duties on government. If such conditions are incorporated into the democratic process it would encourage greater citizen participation by traditionally disadvantaged sectors of society e.g. females, ethnic minorities, less educated and impoverished individuals, who tend to be most under-represented and disengaged from the democratic process.

It is obvious that e-democracy will be effective only if those engaging in

\footnotetext{
${ }^{30}$ Morison, J. 'The Case Against Constitutional Reform' (1998) Journal of Law and Society Vol. 25 No. 4 (December) 532.

${ }^{31}$ Young, I.M. 'Polity and Group Difference: A Critique of the Ideal of Universal Citizenship' (1989) 99 Ethics 269.
} 
the process are knowledgeable and capable of presenting coherent, reasoned arguments. To do this, the public must have access to information that is accurate and unbiased. In this respect it is arguable that the Internet differs from traditional media, many of whom have built up a reputation and audience on the basis of trust, dependent upon accurate information. ${ }^{32}$ While the Internet hosts a wealth of information the validity or accuracy of much of this information can not readily be ascertained. As Barber asserts;

The Net is plethora of information: truth, lies, science and superstition, all thrown together with no internal standards for making judgements ${ }^{33}$

It is suggested that Government should be responsible for providing accurate information, or at least regulating information that may be referred to in the course of a debate concerning government policy. ${ }^{34} \mathrm{Also}$, Ministers could play an important role in stimulating and moulding political debates by engaging in online discussions. It is not intended that their representative role be superseded by the Internet, rather it is envisioned that the will play an important role is identifying threads in discussion groups and ensuring that important issues are brought to the attention of government. In this capacity, the Internet would serve as an adjunct to traditional, face-to-face constituency meetings.

Consequently, it is arguable that one of the greatest problems faced by democracy is the rarity of 'public space' in which rational-critical, discursive political exchanges can occur. The Internet represents a new public sphere for public interaction where democracy could be revitalised. It potentially allows people participating in an interactive discussion group to share a basis of understanding as common ground from which to mediate consensus. As Rheingold observes;

more and more government databases are going on-line at local and national levels. The coexistence of very large and up-to-date collections of factual information in conjunction with a medium that is also a forum for discussion and debate has important implications for the public sphere. $^{35}$

Indeed, citizens can benefit from instant access to factual information (via hyperlinks) in order to support or refute assertions made during discussions. Rheingold asserts that such discussions could;

\footnotetext{
${ }^{32}$ Though it is arguable that traditional media are utilised and manipulated as a form of political control, and ought not to be trusted.

${ }^{33}$ Barber, B. 'Which Technology for which Democracy? Which Democracy for which Technology?' (2001) International Journal of Communications Law and Policy Issue 66.

${ }^{34}$ It is not suggested that Government engage in Censorship, rather that they draw attention to independent reports, and highlight deficiencies in biased, inaccurate reports.

${ }^{35}$ Rheingold (1993) 91.
} 
grow into the real basis for a possible electronic democracy of the future. ${ }^{36}$

It is accepted that Internet technologies are still in their infancy. However, three types of government e-democracy initiatives can be identified. Firstly, online input to formal decision-making e. Scottish Parliament, ${ }^{37}$ which has agreed to accept official public petitions ${ }^{38}$ via the Internet. Second, online consultations with government ministers e.g. Netherlands which guarantees facilitated access to the Minister ${ }^{39}$ and has been used to successfully develop controversial issues. They key to success of such consultations rests in an assurance of participants that the comments will be read and responded to by the relevant minister within an acceptable time period. Thirdly, online parliamentary positions and consultations, such as the Hansard Society, ${ }^{40}$ by hosting a series of invited expert interactive forums in conjunction with the House of Commons and House of Lords committees, in which an invited group discusses a topic from which a high-level report is generated at the request of a parliamentary committee. Nevertheless, Morison and Newman ${ }^{41}$ assert that most governmental websites are not achieving their full potential, because the website creators adhere to the traditional model of communications, which treats the consumer as a passive recipient of information, rather than recognising that a citizen may wish to interact. For example, the UK Citizen's Portal indicates that citizens may wish to contact their MP's but advises them to do so by writing to them at their constituency offices, instead of providing their email addresses. Likewise, it advises citizens of consultations that will be forthcoming, and suggests that they may want to make personal representations at the forum, rather than hosting an on-line discussion forum.

Thus, it is submitted that if the government websites made a concerted effort to incorporate interactive elements into their websites which would foster greater citizen participation in the democratic process. Indeed, the participatory democratic process facilitated by such online initiatives could pose a potential challenge to the conflation of State institutions with the public sphere of debate and association. The Internet allows many, alternative, co-existing 'public spheres' of public interaction. Although the idea of more than one public sphere appears to contradict the utopian vision of democracy, Habermas ${ }^{42}$ accepts that if democracy is to be realised in today's large, complex, interconnected networks of Society, then the

\footnotetext{
${ }^{36}$ Rheingold (1993) 91.

${ }^{37}$ http://www.teledemocracy.org

${ }_{38}$ Petitions are a formal request from one or more people to Parliament.

${ }^{39}$ http://www.rogervanboxtel.nl

40 http://www.democracyforum.org.uk

${ }_{41}$ Morison, J. \& Newman, D.R. (2001) 174.

${ }^{42}$ Habermas, J. (1990) p. 43 in Peters, J.D. (1993) 564.
} 
ideal of a physical collective of mutually consenting members must be rejected. Instead, he suggests that citizens who are not physically co-present can develop 'subjectless' forms of communication. Fraser concurs with this assessment, suggesting that;

A socially egalitarian society requires a public sphere which encompasses many different publics, including at least one common public in which participants can negotiate differences about policy that concerns them all. $^{43}$

Thus, the Internet affords politicians an opportunity to become more accountable to the public, as it potentially allows MP's to engage with and represent their constituents in a more real sense, thereby realising the 'Greek agora' where it was possible for every citizen to participate in dialogue concerning every issue being debated in Parliament. Despite this, it is unlikely that the egalitarian vision of direct democracy through Internet technologies will be realised. It is submitted that this outcome is to be preferred to the potential emergence of a plebiscitary democracy, as Snellen contends that;

Unless direct democratic mechanisms take the relative intensity with which preferences are felt into account, they introduce a dictatorship of successive majorities. They are not adapted to communicate the relative intensity with which opinions and convictions are held. ${ }^{44}$

\section{Conclusion}

In conclusion, it is true to say that the Internet is not a panacea for democratic apathy and atrophy. As Yankelovich stated;

For democracy to flourish, it is not enough to get out the vote. We need better public judgement and we need to know how to cultivate it. ${ }^{45}$

In contrast with the traditional TV and newspaper media, which operate on the basis of one-way communication with a passive audience, the Internet's interactive capabilities encourage debate and discussion. It allows groups with particular interest to form communities independent of physical location. Indeed, the Internet medium of communication has the potential to function as a 'public sphere' locus, connecting large numbers of people in a forum of civic dialogue, in concurrence with the Habermasian ideal of democracy. It also has storage capacity for huge amounts of

\footnotetext{
${ }^{43}$ Fraser, N. 'Rethinking the Public Sphere: a contribution to the critique of Actually Existing Democracy' in Calhoun, C. Habermas and the Public Sphere (Massachusetts: MIT Press 1993) 127.

${ }^{44}$ Snellen, I. 1-2.

${ }^{45}$ Yankelovich, D. Coming to Public Judgement: Making Democracy Work in a Complex World (Syracuse University Press, Syracuse 1991) 11.
} 
information that can be readily accessed by individuals at minimal cost, and used by such individuals to support or refute an argument, thereby facilitating knowledgeable, informed democratic discussions. All of these features combine to confer on the Internet the potential to operate as an electronic agora, an integral element of the democratic process, where citizens actively engage in the democratic process. Moreover, for government it accords an opportunity to reinvigorate communication with constituent communities and engage the attention of a broader crosssection of the population, which can only serve to strengthen the democratic process.

However, the Internet alone will not resolve the issue of democratic apathy and crisis of democratic legitimacy. Much will depend upon policies adopted by governments to foster the role of the Internet in the democratic process. If government websites continue to develop along a 'consumer' model, then the envisioned 'public sphere' may not come to fruition, and an opportunity for democratic renewal may be missed. A vital opportunity to engage the marginalised sectors of society could be lost if the government does not actively seek to incorporate them in the democratic process e.g. by placing computers in schools, community centres etc. and providing training for those who lack computer skills (or assisted access for those with disabilities and literacy problems). Government policies also need to incorporate safeguards to ensure that the Internet is not exploited for purposes antithetical to a democracy, such as generating plebiscitary support, or for the purposes of populist agitation.

Given that Internet technology is still in its infancy and most government sponsored websites to date have been experimental, it is too early to judge whether this opportunity for democratic renewal has been realised by governments. Accordingly it is submitted that either of two alternative visions of democracy may emerge in the next decade: The worst case scenario that can be envisioned is one in which politicians and bureaucrats adhere to the current 'consumer' model of websites, focusing on online service provision, and a 'tokenistic' adoption of online engagement opportunities e.g. online discussions, but retaining existing structures of policy formation so that the public's input is 'worked around' rather than underpinning the democratic process. It is suggested that if this model prevails, then the public will grow increasingly frustrated with the democratic process, and election results such as those delivered by the French electorate will become an endemic norm, which no democratic government can risk.

In contrast, the democratic process may be reinvigorated if governments take deliberate action to create and preserve 'public spaces' and to widen access to the Internet across social, economic and organisational barriers. The adoption of such policies could encourage utilisation of the Internet as an adjunct to face-to-face communications, thereby reinforcing civic 
involvement in the democratic process. It is hoped that governments will seize this opportunity to restore democratic legitimacy. If so, the Internet may form the basis of a Political Revolution, which would be welcomed in many democracies, not least in France. 